\title{
Neurogenic bladder in spinal cord injury patients
}

\author{
This article was published in the following Dove Press journal: \\ Research and Reports in Urology \\ 10 June 2015 \\ Number of times this article has been viewed
}

\section{Waleed Al Taweel \\ Raouf Seyam \\ Department of Urology, King Faisal Specialist Hospital and Research Center, Riyadh, Saudi Arabia}

\begin{abstract}
Neurogenic bladder dysfunction due to spinal cord injury poses a significant threat to the well-being of patients. Incontinence, renal impairment, urinary tract infection, stones, and poor quality of life are some complications of this condition. The majority of patients will require management to ensure low pressure reservoir function of the bladder, complete emptying, and dryness. Management typically begins with anticholinergic medications and clean intermittent catheterization. Patients who fail this treatment because of inefficacy or intolerability are candidates for a spectrum of more invasive procedures. Endoscopic managements to relieve the bladder outlet resistance include sphincterotomy, botulinum toxin injection, and stent insertion. In contrast, patients with incompetent sphincters are candidates for transobturator tape insertion, sling surgery, or artificial sphincter implantation. Coordinated bladder emptying is possible with neuromodulation in selected patients. Bladder augmentation, usually with an intestinal segment, and urinary diversion are the last resort. Tissue engineering is promising in experimental settings; however, its role in clinical bladder management is still evolving. In this review, we summarize the current literature pertaining to the pathology and management of neurogenic bladder dysfunction in patients with spinal cord injury.
\end{abstract}

Keywords: neurogenic bladder, spinal cord injury, urodynamics, intestine, intermittent catheterization

\section{Introduction}

Spinal cord injury (SCI) can occur secondary to spinal column fracture after road traffic accidents or trauma or as a consequence of vascular ischemia or infection. The most common urologic complications following SCI are urinary tract infection (UTI), upper and lower urinary tract deterioration, and bladder or renal stones. ${ }^{1,2}$ One of the most fundamental steps following the initial injury is bladder management. However, many factors are involved in bladder management, including sex, lifestyle issues, hand dexterity, and access to health care providers. When an efficient bladder management program is applied, the patient will experience less incontinence, with improved quality of life. ${ }^{3}$ More than 250,000 people are living with SCI in the USA. The National Spinal Cord Injury Statistical Center reports 40 new cases per million of the population per year. More than $80 \%$ of these individuals exhibit at least some degree of bladder dysfunction. There is no single management program that can work for every patient, and patients will require frequent clinic visits and hospitalizations. In a large cohort study of patients with neurogenic bladder, $40 \%$ attended a urology clinic visit over 1 year, 33\% were hospitalized, and 15\% were in a nursing home. UTIs were responsible for more than $20 \%$ of all 1-year hospitalizations. ${ }^{4}$
Correspondence: Waleed Al Tawee Department of Urology, King Faisal Specialist Hospital and Research Centre, PO Box 3354, Riyadh II 2 II, Saudi Arabia Tel +966 II 4424300

Fax +966 I| 442430 I

Email drwtl@hotmail.com 


\section{Pathophysiology}

To understand the pathophysiology of voiding dysfunction, we should start with normal micturition. Normal micturition requires the coordination of a neuronal circuit between the brain and spinal cord and the bladder and urethra. The sacral micturition center (S2-S4), pontine micturition center, and cerebral cortex are responsible for the facilitation and inhibition of voiding. Parasympathetic efferents from the sacral cord at S2-S4 via the pelvic nerves provide excitatory input to the bladder. Bladder contraction results from muscarinic receptor stimulation. The external sphincter is inhibited through somatic nerves via the pudendal nerve. The sympathetic efferents originate from the intermediolateral gray column T11-L2 and supply the bladder and urethra. These nerves provide inhibitory input to the bladder through the hypogastric nerve. Sympathetic stimulation causes relaxation of the bladder through beta receptor stimulation and contraction of the sphincter through alpha receptor stimulation. ${ }^{5}$

\section{Spinal shock}

Spinal shock occurs following an acute SCI and can last up to 3 months. Autonomic activation of the bladder by the parasympathetic nerves is rendered inactive. The bladder becomes atonic, and there is no conscious awareness of bladder filling. Interruption of the neuraxis below the pons due to SCI eliminates the micturition reflex, which causes urine retention. Initial urodynamic studies should be performed after the patient is beyond the spinal shock phase, and urine retention should be managed by clean intermittent catheterization (CIC) or with an indwelling catheter. After spinal shock, involuntary and uncoordinated bladder contraction might occur and result in reflex bladder function. ${ }^{6,7}$

\section{Suprasacral lesion}

Following spinal shock associated with SCI above S1, reflex bladder function will occur. Consciousness of bladder filling might not be totally absent; however, voluntary inhibition of the micturition reflex is lost. Typical urodynamic findings include detrusor overactivity and detrusor striated sphincter dyssynergia (DESD). Discoordinated contraction will result in high voiding pressure, residual urine volume, and urinary incontinence that, if not treated, will result in upper tract deterioration and renal failure. ${ }^{8,9}$

\section{Sacral lesion}

SCIs at the sacral level result in parasympathetic decentralization of the bladder and denervation of the sphincter. In cases of complete lesion, conscious awareness of bladder filling is lost, and the micturition reflex is absent. Patients will have highly compliant, acontractile bladders with competent but nonrelaxing smooth and striated sphincters that retain some fixed tone. However, low bladder compliance can occur. ${ }^{10,11}$ It has been suggested that an altered sympathetic pathway could explain the decrease in bladder compliance. ${ }^{12}$ The classic outlet findings are a competent but nonrelaxing smooth sphincter and a striated sphincter that retains some fixed tone but is not under voluntary control.

\section{Complications of neurogenic bladder}

The most common complications of neurogenic bladder due to SCI are UTI, urinary stones, and renal impairment. These complications are associated with the pathology of bladder dysfunction itself or occur as a consequence of the use of urinary catheters for drainage.

\section{Urinary tract infection}

Patients with SCI bladder and stable bladder management are prone to repeated UTIs. Symptomatic UTIs continue to pose a significant problem for these patients. Symptomatic UTIs might include fever, foul smelling urine, and/or hematuria. A comparative study followed patients for 1 year and showed that episodes of bacteriuria with fever were significantly more common in patients who were catheterized by someone else than in patients on self-CIC or with indwelling catheters. Patients who exhibited the least frequent episodes of symptomatic UTI were those with external sphincterotomies. ${ }^{13}$

The type of catheter used for CIC in patients with SCI-neurogenic bladder dysfunction might affect the rate of infection. In a prospective randomized study that compared hydrophilic-coated catheters with uncoated polyvinyl chloride catheters, significantly fewer patients using the hydrophilic-coated catheters (64\%) experienced one or more UTIs compared with the control group ( $82 \%$ ) over a period of 1 year. ${ }^{14}$

Several studies have examined the value of prophylactic antibiotics for prevention of UTIs in SCI patients on CIC. A prospective randomized trial evaluated the possible role of trimethoprim-sulfamethoxazole prophylaxis in patients with recent SCI during the first 4 months of CIC during the bladder training phase. A significant reduction in bacteriuria and symptomatic UTI was observed in men in the antibiotic group compared with those on placebo. This difference was not observed in female patients. However, adverse events related to antibiotic treatment and emergence of drug 
resistance were common and limit the usefulness of this treatment regimen. ${ }^{15}$

Another prospective study in patients with SCIneurogenic bladder dysfunction conducted during initial management with CIC found that prophylactic antibiotics significantly reduced bacteriuria but not clinical UTIs. ${ }^{16}$ A meta-analysis examined the benefits and harms of antimicrobial prophylaxis for UTI in patients with SCI. ${ }^{17}$ The authors pooled the results from 15 clinical trials and reached the conclusion that there is no evidence to support the use of prophylactic antibiotics for most patients. Prophylaxis did not significantly decrease symptomatic infections but was associated with a reduction in asymptomatic bacteriuria. Importantly, prophylaxis resulted in a two-fold increase in antimicrobial-resistant bacteria.

Modification of antibiotic treatment regimens might reduce drug resistance. SCI-neurogenic bladder dysfunction on intermittent catheterization and recurrent UTIs require multiple courses of antibiotic therapy that increase the incidence of multidrug-resistant bacteria. A prospective study determined the efficacy of alternate administration of an oral antibiotic once per week to prevent UTIs. Two years of follow-up revealed a significant decrease in symptomatic UTIs from 9.4 to 1.8 per patient-year with no development of new drug-resistant bacteria. ${ }^{18}$

Alternative treatment options for reducing infection include daily administration of methenamine hippurate or cranberry tablets. However, in patients with stable bladder management following SCI, a prospective double-blind study failed to identify any benefit of such regimens in terms of reducing symptomatic UTIs over a follow-up period of 6 months. ${ }^{19}$ An interesting technique to prevent UTI in SCI patients is inoculation of the bladder with the innocuous Escherichia coli strain 83972. With a mean duration of colonization of 12 months, the patients exhibited no symptoms of UTI compared with a mean of 3.1 symptomatic UTIs per year before colonization. Symptomatic UTIs occurred in the patients who were not successfully colonized and after spontaneous loss of colonization. ${ }^{20}$

\section{Urethritis and prostatitis}

To decrease the possibility of urethritis, patients should use CICs and avoid indwelling catheters. Occasionally, blockage of the periurethral glands can cause periurethral abscesses. $E$. coli is the most frequent bacteria in prostatitis. Most antibiotics diffuse poorly into prostatic tissue, and trimethoprim is one of the recommended antibiotics because of its ability to cross the blood-prostatic barrier. ${ }^{21}$

\section{Epididymitis and epididymo-orchitis}

These conditions are catheter-related complications. SCI patients usually will not experience pain, but they might exhibit swelling and occasionally skin redness. Treatment consists of antibiotic therapy. Occasionally, testicular abscesses that require drainage might form. ${ }^{21}$

\section{Bladder stones}

Infections of the bladder with urea-splitting organisms, indwelling catheters, and high residual urine levels are the primary reasons for bladder stone formation. Stone formation might cause severe irritative symptoms and hematuria. Weekly changing of the catheters might decrease the potential for bladder stone formation. ${ }^{22}$

\section{Renal stones}

The overall incidence of renal stones is 3.5\% in patients with neurogenic bladder. The most common are struvite stones. Successful treatment depends on complete elimination of the calculus and eradication of the infection. ${ }^{23}$

\section{Reflux and renal insufficiency}

Vesicoureteral reflux occurs in more than $20 \%$ of patients with neurogenic bladder. This condition is more common when the lesion is suprasacral. High detrusor pressure and reflux are responsible for renal damage and renal failure. The best treatment for reflux is to normalize the detrusor pressure. $^{24}$

\section{Bladder cancer}

The risk of bladder cancer is 20 times higher in spinal cord injury patients compared to the general population, with squamous cell cancer occurring more commonly than transitional cell cancer. The risk factors are UTI, bladder stones, and indwelling catheters. Unfortunately, the diagnosis is usually made in the more advanced stages. ${ }^{25}$

\section{Autonomic dysreflexia}

Autonomic dysreflexia involves a triad of high blood pressure, bradycardia, and sweating, with hot flushes and occasional headaches. It occurs frequently in individuals with SCI at the T6 level or above. ${ }^{26,27}$ Autonomic dysreflexia with elevated blood pressure is a strong risk factor for intracerebral hemorrhage, so should be treated as a medical emergency. Afferent peripheral stimulation below the SCI lesion provokes autonomic dysreflexia. Distension of the bladder and then the rectum is the most common cause. However, it can be caused by UTI, bladder stones, cystoscopy, gastrointestinal 
diseases, such as acute abdomen and gastric ulcer, fractures, and pressure ulcers. To treat autonomic dysreflexia, the triggering factor should be removed. ${ }^{28}$

\section{Evaluation of patients with neurogenic bladder}

The initial evaluation includes history-taking and a voiding diary. A focused physical examination is essential to evaluate the pelvic anatomy and the nervous system. The examiner should determine the level of the spinal motor lesion, the extent of injury, ie, whether it is complete or incomplete, limb tone, rectal tone, and the bulbocavernosus reflex. ${ }^{29}$ To properly assess the patient's symptoms, a validated neurogenic bladder symptom score was recently developed as a tool to measure urinary symptoms and their consequences in patients with acquired or congenital neurogenic bladder. We highly recommend the use of this questionnaire or the symptoms score during patient assessment. ${ }^{30}$ Urinalysis, urine culture and sensitivity, serum blood urea nitrogen/ creatinine, creatinine clearance, urodynamics, and urinary tract imaging should be performed during the initial evaluation of SCI patients. ${ }^{31,32}$ Urologic follow-up evaluations of patients with neurogenic bladder are typically performed yearly. We recommend urinalysis every 6 months, urine culture whenever the patient is symptomatic, ultrasound of the upper tract every 6 months, and urodynamic evaluation every 1-2 years. Patients with high detrusor pressure or decreased compliance require urodynamic evaluation within 12 months of treatment. ${ }^{33}$ Detection of hydronephrosis can be used as a marker of badly managed neurogenic bladder.

\section{Urodynamics}

Urodynamics are the mainstay for evaluation of neurogenic lower urinary tract dysfunction. These assessments include urinary flowmetry, bladder cystometry, electromyogram, Valsalva leak point pressure, and detrusor leak point pressure (DLPP). Urodynamic evaluations provide the most definitive diagnoses of abnormalities in the bladder and urethra during the filling/storage phase. The initial urodynamic studies should be delayed until after the spinal shock phase has passed. Because the anatomic site of the SCI does not predict bladder and urethral function, management should be based on urodynamic findings rather than on findings from the neurologic evaluation. ${ }^{34}$

Initial studies to identify patients who are at risk for upper tract disease should be conducted early because the effects of the disease on the urinary tract can be silent. We use a high DLPP as a predictive marker of upper tract deterioration.
It has been suggested that a DLPP greater than $40 \mathrm{~cm} \mathrm{H}_{2} \mathrm{O}$ is a risk factor for upper tract deterioration. ${ }^{35}$ The goals of assessment are to observe the maintenance of low bladder pressures, decrease the risk of infection, maintain continence, and prevent upper tract deterioration. ${ }^{36}$ Lower urinary tract function is subject to change in most cases of neurogenic bladder; hence, regular urodynamic follow-ups are warranted. In a long-term study, the treatment strategy for neurogenic bladder dysfunction in SCI patients had to be modified in all patients. ${ }^{37}$ Videourodynamic studies combine fluoroscopic voiding cystourethrography with multichannel urodynamics to provide the most comprehensive assessment of the lower urinary tract in SCI patients. When vesicoureteral reflux occurs, the volume and pressure at which the reflux is initiated can be documented. Videourodynamic studies are the definitive tests for diagnosis of DESD during detrusor contraction. ${ }^{38}$ We highly recommend videourodynamics for all patients with neurogenic bladder.

\section{Cystoscopy}

Cystoscopy is not useful in the initial evaluation of neurogenic bladder but becomes very important for assessing lower urinary tract complications. We recommend cystoscopy when hematuria, difficult catheterization, or recurrent blockage of an indwelling catheter is present.

\section{Conservative management}

Conservative management is the most frequently applied treatment option in neurogenic bladder. Conservative management requires patient education and might include timed voiding, the Valsalva and Credé maneuvers, medications, intermittent catheterization, or an indwelling urinary catheter. Regular bladder emptying with or without anticholinergic medications is important to prevent UTIs, upper tract damage, and incontinence.

The type of bladder management used and frequency of urinary incontinence strongly influence health-related quality of life. ${ }^{39}$ Several factors influence patient choice for bladder management. Patients are likely to choose treatments that they perceive as convenient to use and will maintain continence. ${ }^{40}$ In a cross-sectional study of patients with SCI, only $21 \%$ reported normal voiding. ${ }^{39}$ In addition to frequency of incontinence, health-related quality of life is affected by the type of bladder management. The worst mental status scores are associated with attendants performing CIC and use of indwelling urethral catheters or indwelling suprapubic catheters. ${ }^{39}$ A prospective study evaluated the psychologic and social status of patients using CIC for SCI-associated 
neurogenic bladder dysfunction. The patients generally reported reduced health-related quality of life scores in all health domains. ${ }^{41}$

\section{Patient education}

Patients should be educated about bladder management immediately after SCI to avoid complications; however, less than $50 \%$ of SCI patients have good knowledge about bladder management and pressure ulcers after being discharged. ${ }^{42}$ Education of community health professionals about the delayed complications of SCI and good communication between doctors, patients, caregivers, and community health professionals are likely to improve the care of SCI patients following discharge from SCI centers. ${ }^{43}$

\section{Credé maneuver}

Various maneuvers can be used to empty the bladder, the most common being the Credé and Valsalva maneuvers. However, the Credé and Valsalva maneuvers are generally not recommended as primary methods of bladder emptying. Potential complications of the Credé and Valsalva maneuvers include high bladder pressure, abdominal bruising with the Credé method, hernia, and hemorrhoids. Long-term use of the Credé maneuver to evacuate the bladder is not safe. This conclusion was reached in a cross-sectional study of SCI patients with flaccid bladders 20 years after an earthquake in the People's Republic of China. ${ }^{44}$ Most of the patients exhibited residuals exceeding $100 \mathrm{~mL}$, and half exhibited more than $300 \mathrm{~mL}$ of residual urine following the Credé maneuver. Urologic complications were common and included pyuria $(82 \%)$, urinary lithiasis $(31 \%)$, ureteral dilatation $(60 \%)$, hydronephrosis (35\%), and renal damage (16\%). Upper urinary tract deterioration was more common in men. Women who perform the Credé maneuver might have an anatomic advantage over men. However, in a prospective, long-term follow-up of men and women with SCI-induced neurogenic bladder dysfunction, no specific method of bladder management was observed to cause renal impairment in women. ${ }^{45}$ The only subset of patients in which significant deterioration was observed was men with quadriplegia and ileal conduits when compared with the women.

\section{Clean intermittent catheterization}

CIC is the preferred method of bladder emptying in SCI patients. This method improves patient self-care and reduces barriers to sexual intercourse when compared with the use of an indwelling catheter. CIC alone or in combination with another bladder-emptying method is the most frequently used method of bladder emptying. ${ }^{46}$ We recommend CIC every 4-6 hours, depending on fluid intake and frequency of incontinence. In a study of 161 patients, CIC was the most frequently used bladder program and had the lowest risk of complications. ${ }^{47}$ UTI is the most frequent complication of intermittent catheterization. Several studies have shown that there is a $10 \%$ prevalence of asymptomatic UTI and a more than $50 \%$ prevalence of symptomatic UTI. ${ }^{48}$ Regular use of antimicrobial prophylaxis in neurogenic bladder caused by SCI is not supported. ${ }^{17} \mathrm{~A}$ randomized controlled trial in patients with SCI-neurogenic bladder dysfunction indicated an advantage of using sterile catheterization (UTI incidence $28.6 \%$ ) compared with a nonsterile catheterization technique (UTI incidence 42.4\%). However, the cost was nearly threefold greater in the sterile catheterization group, even with the reduced cost of antibiotic use. ${ }^{49}$ While this study did not find any difference in terms of catheter-related bleeding, patients who used hydrophilic-coated catheters experienced fewer UTIs than those who used uncoated polyvinyl chloride catheters. ${ }^{14}$ The hydrophilic type of catheter was superior to its nonhydrophilic counterpart, as indicated by significantly lower numbers of inflammatory episodes, UTIs, and bleeding incidents, and a higher satisfaction level. ${ }^{50}$ Prelubricated nonhydrophilic catheters are associated with a lower UTI rate, better patient satisfaction, and less hematuria compared with Nélaton catheters. ${ }^{51}$

Negative effects of CIC have been reported in other studies. Patients with SCI-neurogenic bladder dysfunction who are on CIC have been reported to experience erectile dysfunction and poor sexual activity and to have higher degrees of depression than the normal population. ${ }^{52,53}$

\section{Indwelling catheters}

Indwelling urethral catheter drainage is not recommended in SCI patients unless they have difficulty self-catheterizing; for example, in cases of quadriplegia or in the presence of urethral abnormalities. An indwelling urethral catheter increases the risks of UTI, renal impairment, bladder stone formation, urethral stricture, urethral erosion, and bladder cancer. ${ }^{54,55}$ A study of patients with SCI-neurogenic bladder dysfunction who were followed for more than 20 years indicated that indwelling catheters, whether suprapubic or urethral, were associated with increased prevalence of upper tract scarring and caliectasis when compared with CIC, sphincterotomy, or vesicostomy. An alarming incidence of bladder cancer was reported, with six of 81 patients developing this condition. The authors recommended that patients with indwelling catheters require regular follow-up with 
imaging and cystoscopy. ${ }^{56}$ However, annual cystoscopy screening in patients with SCI and indwelling catheters for a period of 6 years did not result in early detection of bladder cancer. The authors diligently followed up patients with cystoscopy under general anesthesia, urine cytology, and bladder biopsies. Bladder cancer did develop in four of the 59 patients, but these cases were diagnosed based on presenting symptoms rather than screening. The authors concluded that screening cystoscopy is not recommended for SCI patients with indwelling catheters. ${ }^{57}$

Suprapubic catheterization has certain advantages. A suprapubic catheter is typically easier to manage in terms of hygiene and catheter changes. Such catheters eliminate the risk of urethral stricture and erosion and result in high levels of patient satisfaction. Indeed, $90 \%$ of patients prefer suprapubic catheters over urethral catheters. ${ }^{58}$ Additionally, patients on suprapubic catheters show less frequent epididymitis and iatrogenic hypospadias. ${ }^{59} \mathrm{~A}$ suprapubic catheter is a valuable option for urinary management in quadriplegic patients; however, $65 \%$ of these patients develop a bladder stone. ${ }^{60}$ Suprapubic catheterization care is important to reduce morbidity in patients with SCI-neurogenic bladder dysfunction. At a mean follow-up of 58 months, one study reported no renal deterioration, vesicoureteral reflux, or bladder carcinoma ${ }^{61}$ In this study, catheter care included weekly irrigation and exchange every 2 weeks.

There are certain advantages to the use of CIC over indwelling urethral catheters in patients with SCI-neurogenic bladder dysfunction. In a large group of patients with SCI, bladder compliance was better maintained in patients with spontaneous voiding and CIC than in patients with indwelling catheters. Furthermore, low compliance was associated with significantly higher rates of vesicoureteral reflux, upper tract deterioration, pyelonephritis, and upper tract stones. ${ }^{62}$ At a mean follow-up of 18 years, the data indicated a significantly lower complication rate with CIC (27.2\%) than with chronic urethral catheterization (53.5\%), spontaneous voiding (32.4\%), or suprapubic catheterization $(44.4 \%) .{ }^{60} \mathrm{In}$ female patients with SCI-neurogenic bladder dysfunction, CIC was associated with a significantly lower complication rate $(17 \%)$ compared with padding $(40 \%)$ and indwelling catheter (greater than 200\%) groups. ${ }^{63}$

\section{Anticholinergic medications}

Anticholinergic treatment is the first-line therapy for neurogenic detrusor overactivity. This treatment works by blocking cholinergic transmission at muscarinic receptors. Anticholinergic agents have similar efficacy; however, they have different side effect and tolerability profiles that depend on their muscarinic receptor selectivity and the rate of drug distribution. Several studies have shown that anticholinergic treatment increases bladder capacity, reduces bladder pressure, and improves compliance and quality of life. The majority of the studies have examined oxybutynin immediaterelease, trospium chloride immediate-release, propiverine immediate-release, and propiverine extended-release. ${ }^{64,65}$

Anticholinergic drugs that bind M1 receptors might produce impairments of memory and cognition. Agents that bind M2 receptors can produce QT interval prolongation that causes tachycardia and arrhythmias. Anticholinergic drugs that bind M3 receptors might produce visual blurring, xerostomia, and constipation. Different routes of application have been used to reduce the side effects of oral anticholinergics. A transdermal oxybutynin system was found to be efficacious in SCI patients with neurogenic detrusor overactivity and was well tolerated at up to three times the standard dose; however, skin irritation was a common side effect. ${ }^{66}$ Intravesical therapy with oxybutynin has been shown to be effective and helps to reduce the systemic side effects associated with oral administration of this drug. ${ }^{67}$

A combined antimuscarinic treatment has been used in refractory neurogenic bladder; despite the increased side effects, the combined treatment delays the need for other more invasive treatments. ${ }^{68} \mathrm{~A}$ higher dose of oxybutynin (30 mg) has been used to improve patient symptoms; this dose was found to be effective, safe, and well tolerated. ${ }^{69}$

\section{Surgical management}

Early management of neurogenic detrusor overactivity typically consists of anticholinergics and CIC. The goal of treatment is to achieve continence and protect the upper urinary tract via an increase in bladder capacity and a decrease in intravesical pressure. Patients who fail treatment either because of decreased efficacy or intolerance of side effects have various treatment options, many of which are surgical. Surgical treatment involves promoting storage function, decreasing outlet resistance, and/or achieving continence. A spectrum of surgical procedures, ranging from minimally invasive to complex, has been reported for the management of neurogenic bladder in SCI patients. Attempts to relax the external sphincter have included the endoscopic injection of the sphincter with botulinum toxin, sphincterotomy, and stent insertion. Reducing bladder tone and increasing capacity are the primary goals of botulinum toxin injection in the detrusor and augmentation cystoplasty. These procedures include clam cystoplasty, use of the intestines, and tissue engineering. Incompetent sphincters are treated with an artificial urinary 
sphincter (AUS), abdominal slings, or a transobturator tape procedure. Less commonly reported are attempts to achieve coordinated bladder emptying via neuromodulation and nerve grafting, and muscle grafting has been reported in cases of acontractile bladder. Finally, circumventing the bladder with urinary diversion as a last resort have been reported. The details of surgical management are reported further into this paper.

\section{Surgery to promote urine storage Increasing functional bladder capacity}

\section{Botulinum toxin}

Botulinum toxin is a minimally invasive treatment that might achieve the therapeutic goals. This treatment was first used in patients with SCI in 2000 and was subsequently shown to have good efficacy and tolerability both in terms of subjective and objective outcomes. ${ }^{70-77}$ In August 2011, botulinum toxin was finally approved by the US Food and Drug Administration for the treatment of adults with neurogenic detrusor overactivity who fail treatment with anticholinergic medications. $^{78}$

Studies that have used 300 units of botulinum-A toxin report increases in mean reflex volumes and maximum cystometric bladder capacities of 216 to $416 \mathrm{~mL}$ and 296 to $480 \mathrm{~mL}$, respectively, and decreased maximum detrusor voiding pressures of 66 to $35 \mathrm{~cm}$ water. ${ }^{70}$ The effects of treatment lasted at least 9 months. A particular benefit in patients with tetraplegia was the disappearance of autonomic dysreflexia. Prospective randomized studies have confirmed that treatment with botulinum toxin is associated with a significant reduction in urinary incontinence and improvements in urodynamic parameters and quality of life for patients with SCI. ${ }^{71,73}$ No differences between doses of 200 units and 300 units were found in terms of tolerability, efficacy, or duration of effect. This treatment may be repeated several times over a period of years. Botulinum toxin has been shown to be equally effective in initial and subsequent repeat treatments for up to 6 years. ${ }^{7-77}$

\section{Cystoplasty}

Bladder augmentation and urinary diversion are surgical interventions that are considered only after less invasive treatment options have been exhausted (Table 1). ${ }^{79,80}$

\section{Augmentation cystoplasty/enterocystoplasty}

Bladder augmentation with a detubularized intestinal segment has been successful in increasing bladder capacity and reducing intravesical pressure due to the final spherical configuration. In an intermediate-term to long-term report, Linder et al found that augmentation cystoplasty was a viable treatment option for selected patients with neurogenic bladder. ${ }^{81}$ A more recent study reported the preoperative and postoperative results of videocystometrograms and patient satisfaction based on a validated questionnaire. This group reported a significant postoperative improvement in bladder capacity and a significant decrease in intravesical pressure. ${ }^{82}$

Augmentation with an ileal segment is effective and safe in SCI patients. A retrospective study followed patients for nearly 8 years after augmentation for neurogenic bladder. Following surgery, mean bladder capacity increased from $115 \mathrm{~mL}$ to $513 \mathrm{~mL}$. The patients were able to spontaneously $(10 \%)$ or were required to perform CIC to empty their bladders (72.5\%). Complications included episodes of UTI $(65 \%)$, diarrhea $(7.5 \%)$, urinary incontinence $(10 \%)$,

Table I Commonly reported augmentation cystoplasty

\begin{tabular}{|c|c|c|}
\hline Augmentation method & Advantages & Disadvantages \\
\hline $\begin{array}{l}\text { Ileal segment detubularized } \\
\text { patch }\end{array}$ & Bladder capacity may increase to $>500 \mathrm{~mL}$ & $\begin{array}{l}\text { Mucus production, formation of bladder calculi, } \\
\text { bacterial colonization, metabolic acidosis, growth } \\
\text { retardation, vitamin BI } 2 \text { deficiency, vesical malignancy, } \\
\text { diarrhea, urinary incontinence, upper tract stones }\end{array}$ \\
\hline Colonic patch & Decreased risk for bowel obstruction & $\begin{array}{l}\text { Bowel dysfunction, diarrhea, fecal incontinence and } \\
\text { reintervention, generates more pressure than ileum }\end{array}$ \\
\hline Gastrocystoplasty & $\begin{array}{l}\text { May be used in patients with chronic renal } \\
\text { impairment and patients with short bowel } \\
\text { Associated with less mucus production and } \\
\text { urinary tract infection }\end{array}$ & $\begin{array}{l}\text { Intermittent hematuria, metabolic alkalosis, hematuria- } \\
\text { dysuria syndrome, higher risk of malignancy, high } \\
\text { incidence of reoperations and surgical complications }\end{array}$ \\
\hline $\begin{array}{l}\text { Autoaugmentation } \\
\text { myectomy/myotomy }\end{array}$ & $\begin{array}{l}\text { Simple to perform } \\
\text { Not precluding subsequent enterocystoplasty } \\
\text { No mucus production } \\
\text { Extraperitoneal approach } \\
\text { Shorter operative time }\end{array}$ & $\begin{array}{l}\text { Fibrous infiltration, poor outcome in patients with } \\
\text { neurogenic bladder } \\
\text { Best results are limited to patients with a close to } \\
\text { normal capacity and poor compliance }\end{array}$ \\
\hline
\end{tabular}


reservoir calculi (32.5\%), and new-onset upper tract stones $(22.5 \%){ }^{83}$

Augmentation cystoplasty with a colonic patch has been reported for patients with SCI-neurogenic bladder dysfunction. ${ }^{84}$ Twelve patients underwent this procedure with concomitant AUS implantation. All of these patients were continent on CIC at a mean follow-up of 15 months. The upper tracts improved or remained stable and the autonomic dysreflexia disappeared. At a mean follow-up of 5.4 years, there was no difference between patients who had undergone Hautmann enterocystoplasty and those who had undergone clam cystoplasty in terms of urodynamic or clinical results. ${ }^{85}$ Refractory neurogenic bladder in SCI patients can be treated with supratrigonal cystectomy and reconstruction with a Hautmann pouch. A concomitant stress incontinence procedure can also be used. A retrospective study reported partial or complete improvement of continence in $74 \%-90 \%$ of patients. ${ }^{86}$ There was also a significant improvement in urodynamic findings. However, the complication rate was $38 \%$; these were mostly grade 2 , but notably included bowel dysfunction, diarrhea, fecal incontinence, and need for reintervention.

With recent improvements in both laparoscopic and robot-assisted techniques, it is clear that the technical steps of an enterocystoplasty can be satisfactorily and effectively performed laparoscopically or robotically. ${ }^{87-89}$

Patients are at risk of long-term complications after bladder augmentation. The complications that are most commonly observed include production of mucus, formation of bladder calculi, bacterial colonization, metabolic acidosis, growth retardation, and vitamin B12 deficiency. ${ }^{90-96}$ Intestinal augmentation cystoplasty poses a risk for development of latent vesical malignancy. However, surveillance cystoscopy has not been found to be useful in detecting bladder cancer in these patients primarily within 15 years of surgery. Worrisome symptoms, such as hematuria, suprapubic pain, or recurrent UTI, warrant full investigations that include cystoscopy and computed tomography. ${ }^{97}$ Augmentation cystoplasty-associated urothelial carcinomas are aggressive and have distinct morphologic, immunohistochemical, and genetic characteristics. ${ }^{98}$ In patients with congenital bladder dysfunction (ie, exstrophy and posterior urethral valves), ileal/colonic bladder augmentation itself is not associated with an increased risk of bladder malignancy. However, immunosuppression is an independent risk factor for malignancy in these patients. ${ }^{99}$

\section{Gastrocystoplasty}

For patients with chronic renal impairment, gastrocystoplasty has been introduced as an alternative to colon-related or ileum-related procedures due to acid-secreting ability. ${ }^{100}$ In short bowel syndrome, this procedure can be an alternative to ileocystoplasty. Advantages of using the stomach are less production of mucus and fewer UTIs. However, gastrocystoplasty is associated with intermittent hematuria, metabolic alkalosis, and hematuria-dysuria syndrome. Children with incontinence experience more severe symptoms of hematuria-dysuria syndrome. This is a more significant problem in children with normal bladders and urethral sensation. ${ }^{101-103}$ The published data do not indicate whether gastrointestinal bladder augmentation is an independent risk factor for cancer compared with the risk associated with a congenitally abnormal bladder. However, the risk of cancer is 14-15 times higher with gastric augmentation compared with the 7-8-fold risk associated with ileal or colonic augmentation in patients with congenital bladder anomalies. ${ }^{104}$ Currently, we do not recommend the use of gastric segments for reconstruction of the lower urinary tract due to the high incidence of reoperations and complications. ${ }^{105}$

\section{Autoaugmentation (detrusor myectomy/myotomy)}

For selected patients, autoaugmentation might be a viable option that offers certain advantages over enterocystoplasty, ie, simplicity of performance and the fact that it does not preclude subsequent enterocystoplasty when required. In 1989, Cartwright and Snow were the first to describe the results of this technique in dogs and its clinical application. ${ }^{106}$ These authors found that partial detrusorectomy appears to function as an autoaugmentation and offers possible advantages over enterocystoplasty in selected patients. ${ }^{106}$ The advantages of this procedure are the lack of mucus production, the extraperitoneal approach, and the shorter operative time. However, the autoaugmented area is characterized by a fibrous infiltrate with an increase in thickness of 500\% compared with the thickness immediately after augmentation. The development of a thin layer of fibrosis between the bladder mucosa and the peritoneum can cause a lack of improvement. ${ }^{107}$ Several reports have indicated poor outcomes in patients with neurogenic bladder. ${ }^{108,109}$ MacNeily et al found that autoaugmentation by detrusor myotomy is not effective in the management of congenital neuropathic bladder. ${ }^{110}$ It appears that the best outcomes can be expected in patients with good capacity but poor compliance. ${ }^{111}$

\section{Seromuscular enterocystoplasty}

Seromuscular enterocystoplasty is a technique that aims to combine the advantages of urothelial preservation and intestinal augmentation. The early experimental work used 
denuded segments of bowel that were grafted with a patch of the bladder mucosa to augment the bladder following partial or total cystectomy. ${ }^{112}$ The results suggest that the presence of the bladder urothelium and lamina propria adjacent to the intestinal patch submucosa and muscularis mucosa might prevent contraction of the intestinal patch. Dewan and Stefanek reported the first clinical use of seromuscular colocystoplasty. ${ }^{113}$ Jednak et al reported that seromuscular colocystoplasty lined with urothelium is a viable alternative to standard bladder augmentation. Comparatively, the incidences of bladder calculi, mucus production, metabolic disturbances, and perforations appear to be low during shortterm follow-up. ${ }^{114}$ Seromuscular colocystoplasty lined with urothelium has proven to be an effective method for bladder augmentation in patients with an AUS and those with planned simultaneous AUS implantation. However, this procedure is not recommended at the time of seromuscular colocystoplasty with urothelium lining to construct a continent catheterizable channel. ${ }^{115}$ The first published report indicated no mucus production and excellent continence rates for patients with neurogenic bladder, but disappointing results for patients with bladder exstrophy. ${ }^{116}$ Bladder distension is important for achieving optimal results. Seromuscular augmentation without placement of an intravesical mold was associated with worse outcomes. ${ }^{117}$

\section{Increasing bladder outlet resistance Artificial urinary sphincter}

An AUS can be used to treat patients with stress urinary incontinence due to neurogenic bladder dysfunction associated with SCI. This procedure is associated with a high revision rate in the long-term. The 10-year experience of periprostatic insertion of AUS has been retrospectively reviewed. Fifty-one males with neurogenic bladder and sphincter deficiency underwent this procedure. In $69 \%$ of these patients, the etiology was SCI. The patients who had detrusor overactivity (39\%) underwent concomitant bladder augmentation. At follow-up (mean 83 months), 74\% of the patients had no or moderate incontinence between CICs that spanned at least 4 hours. Postoperative morbidity (19\%) was primarily due to UTI. ${ }^{118}$ A retrospective analysis of modified implantation at the bladder neck, which utilized a port rather than a pump, reported that this technique was effective and safe at 8 -year follow-up. The reported cure rate was $90 \%$ and the revision rate was $35 \% .^{119}$

In contrast, a comparison of AUS implantation for neurogenic and non-neurogenic incontinence did not indicate a favorable outcome for the neurogenic group. ${ }^{120}$ The authors used the AMS $800^{\mathrm{TM}}$ AUS in 38 patients and followed them for a mean of 6 years. The neurogenic etiologies included SCI, pelvic trauma, and spina bifida. Non-neurogenic incontinence was due to prostatectomy or hysterectomy. Only two of 13 patients in the neurogenic group did not require revision, and only three remained completely dry. In contrast, seven of 17 patients in the non-neurogenic group did not require revision, and eleven were completely dry. The nonmechanical failure rate of the AUS was significantly higher in the neurogenic group.

A retrospective study addressed the question of whether the timing of AUS placement relative to augmentation enterocystoplasty affected the outcome. ${ }^{121}$ AUS implantation was simultaneous in eleven patients, prior to cystoplasty in seven, and after cystoplasty in 12 . The outcomes did not indicate any significant difference. Notably, however, the two patients who had sphincter erosions had injury of the augmented bladders during surgery or belonged to the simultaneous insertion group. The authors attributed the comparable success rates with these three surgical approaches to adequate bowel preparation and maintenance of sterile urine.

Robotic-assisted AUS insertions were reported recently for six patients with stress urinary incontinence following SCI. The AUS cuff were placed around the bladder neck. Since the initial use of this technique in January 2011, the authors have reported no complications. ${ }^{122}$ It would be interesting to compare the long-term safety and efficacy of this novel technique with that of traditional open surgical methods.

\section{Transobturator tape procedure}

Transobturator suburethral tape surgery is widely used to treat female stress incontinence. The application of transobturator tape in women with paraplegia or quadriplegia due to SCI and stress incontinence was recently reported. ${ }^{123}$ Of nine patients who underwent the procedure, only three were cured or improved, and one experienced urethral erosion. The authors concluded that the results were unfavorable for this group of patients.

\section{Puboprostatic sling}

The results reported for autologous sling surgery in male patients with stress incontinence secondary to neurogenic bladder are favorable. ${ }^{124}$ Patients were selected based on fluorourodynamic studies. In 12 adult men, nine of whom had SCI, puboprostatic sling placement distal to the prostatic urethra with or without bladder augmentation resulted in a significant success rate of $83 \%$. These patients were 
either completely dry or experienced minimal leak on CIC. No complications arising from this surgery were reported. The authors concluded that puboprostatic sling repair is safe and effective in carefully selected male patients with neurogenic stress incontinence.

\section{Facilitation of bladder emptying}

DESD in SCI patients is typically treated with antimuscarinics and catheterization. Other treatment options include external sphincterotomy, urethral stents, and intrasphincteric injection of botulinum toxin. ${ }^{32}$ Transurethral sphincterotomy might relieve autonomic dysreflexia in SCI patients with lesions above the thoracic 6 level who are unable to perform intermittent catheterization. A study of such patients reported subjective relief of autonomic dysreflexia and significant decreases in blood pressure and post-void residual urine volume for a mean of 5 years following transurethral sphincterotomy. ${ }^{125}$

\section{Circumventing the problem: urinary diversion}

Conduit urinary diversion might be a good option for management of neurogenic bladder with decreased compliance and upper tract deterioration or severe urinary incontinence. The ileal conduit was introduced by Bricker and has stood the test of time due to its relatively shorter construction time and the familiarity of urologists with this procedure. The reported outcomes were good to fair in only $50 \%$ of patients, with a $25 \%$ mortality rate, resulting mainly from urinary tract complications that occurred several years after the procedure and were attributable to recurrent UTIs. ${ }^{126-128}$ However, contemporary studies have reported better results, with rates of preservation of renal function reaching $100 \% .{ }^{129,130}$ However, major long-term complications have been encountered with ileal conduit diversion, including pyocystitis, stomal bleeding and irritation, metabolic acidosis, and urolithiasis. A prospective study in patients with neurogenic bladder dysfunction secondary to SCI or multiple sclerosis reported that cystectomy and ileal conduit urinary diversion improved urinary quality of life by decreasing the limitations and constraints induced by urinary disorders but had no effect on general quality of life. ${ }^{131}$

\section{Other surgical treatments}

\section{Neuromodulation/electrical stimulation}

Transcutaneous electrical stimulation of the bladder in SCI patients resulted in significant improvements in bladder capacity of greater than $100 \mathrm{~mL}$, reductions in residual urine of $80 \mathrm{~mL}$, and decreases in maximum intravesical pressure at peak flow. ${ }^{132}$ These effects were persistent over the 2-year post-treatment period. Additional studies are required to support these results.

\section{Nerve grafting/nerve transfer}

A novel technique has been described by a research group in the People's Republic of China. These investigators attempted to innervate the bladder below the level of complete SCI to produce urination by Achilles tendon-to-bladder reflex contractions via an intact S1 dorsal root. Nine of 12 paraplegic patients with bladder hyperreflexia and DESD had significant urodynamic improvement to nearly normal storage and synergic voiding. These patients showed an increase in bladder capacity from $258 \mathrm{~mL}$ to $350 \mathrm{~mL}$, a decrease in residual urine from $214 \mathrm{~mL}$ to $45 \mathrm{~mL}$, no UTIs, and recovery of renal function. ${ }^{133}$ In a subsequent paper, these investigators reported the results from nine patients with low conus medullaris lesions involving S2-S5. ${ }^{134}$ The ventral root of $\mathrm{S} 1$ was anastomosed to the distal ends of the $\mathrm{S} 2$ and S3 ventral roots. The authors reported that seven patients regained satisfactory bladder control for 8-12 months.

\section{Muscle grafts}

Microvascular transplantation of the latissimus dorsi muscle to wrap the bladder has been reported in eleven patients with bladder acontractility, which is attributable to SCI in seven cases. ${ }^{135}$ Ten patients regained volitional voiding, and eight required no catheterization during at least 1 year of follow-up.

\section{Urethral stents}

The initial success rate of UroLume ${ }^{\circledR}$ stent placement for SCI-neurogenic bladder dysfunction has been reported. ${ }^{136}$ In a prospective multicenter study in North America, 153 patients were recruited based on a urodynamic diagnosis of DESD. Significant improvements were observed in voiding pressure and residual urine. Ten patients required removal of the stent, and 13 patients underwent secondary surgery for bladder neck obstruction. The authors concluded that the UroLume device is an attractive treatment option for SCI-associated DESD due to the ease of implantation and minimal morbidity. A prospective comparison of the UroLume device and external sphincterotomy in men with SCI has been reported. ${ }^{137}$ Eligible patients were able to choose which treatment they wished to receive. Both groups showed comparable and significant improvement of urodynamic parameters after surgery. Placement of a UroLume was associated with a significantly shorter operative time, a shorter hospital stay, and less bleeding compared with sphincterotomy. Six of the 
26 patients in the UroLume group developed migration or obstruction. Five of the 20 patients in the sphincterotomy group experienced complications that included bleeding, obstruction, or erectile dysfunction. The authors concluded that they favored the UroLume due to its ease of use, lower cost, and increased safety.

Memokath ${ }^{\circledR}$ stents constitute an additional option for the treatment of DESD in men with SCI. A retrospective analysis of 10 years of data initially yielded encouraging results, including relief of dysreflexic symptoms and elimination of DESD on pressure flow urodynamics. ${ }^{138}$ However, during long-term follow-up, 30 of 33 Memokath stents were removed, giving a mean working life of 21 months. Indications for removal included stent migration in seven cases and blockage in 14 cases. The authors of this report concluded that insertion of the Memokath stent must be carefully considered and that its role might be limited to selected patients.

\section{Bladder tissue engineering}

There is limited clinical experience with tissue engineering for bladder augmentation. Although the idea was conceived in the $1950 \mathrm{~s}$, and a plethora of natural and synthetic biomaterial scaffolds has been used in experimental animals, their clinical application remains a formidable challenge. ${ }^{139}$ In a metaanalysis of 28 preclinical and two clinical studies, the reviewers found a poor correlation between the initial experimental successes in healthy animals and those reported in clinical trials. ${ }^{140}$ In the first clinical study, seven patients with neurogenic bladder due to myelomeningocele underwent bladder augmentation using autologous bioengineered constructs. ${ }^{141}$ After nearly 4 years of follow-up, bladder pressure had decreased while capacity and compliance had increased. In contrast, the second clinical study did not report similar success. ${ }^{142}$ Augmentation cystoplasty was performed in children with spina bifida using autologous cell-seeded biodegradable scaffolds. There was no significant clinical improvement in any of the nine patients at 3-year follow-up. Significant adverse effects, including bladder rupture, occurred in four patients. The authors concluded that concerns over the safety of the procedure outweighed its possible benefits. In a recent study of eight patients with neurogenic bladder, two of which were due to SCI, augmentation cystoplasty was performed using small intestinal submucosal porcine grafts as scaffolds for bladder regeneration. ${ }^{143}$ At 12 months, significant increases in bladder capacity and compliance and a decrease in maximum detrusor pressure were observed. While these results are encouraging, longer follow-up is required to assess for any subsequent fibrosis and contracture.

\section{Conclusion}

Neurogenic bladder dysfunction secondary to SCI is a challenging condition that might pose a significant risk to patients. Appropriate evaluation and understanding of the underlying pathology facilitate a tailored treatment plan to maintain the upper tracts, promote continence, and prevent complications. A myriad of medical and surgical approaches are available for achieving these goals. A stepwise management plan might include anticholinergics and CIC. Minimally invasive surgery is a second-line treatment for those who fail or cannot tolerate medical treatment. Bladder augmentation and urinary diversion are last resorts in the management plan. Many novel and promising surgical approaches have been reported, both in experimental animal models and in the clinic. Which of these techniques will provide the most robust clinical benefit in the long term remains to be determined.

\section{Disclosure}

The authors report no conflicts of interest in relation to this work.

\section{References}

1. Noreau L, Noonan VK, Cobb J, Leblond J, Dumont FS. Spinal cord injury community survey: a national, comprehensive study to portray the lives of Canadians with spinal cord injury. Top Spinal Cord Inj Rehabil. 2014;20(4):249-264.

2. Shingleton WB, Bodner DR. The development of urologic complications in relationship to bladder pressure in spinal cord injured patients. J Am Paraplegia Soc. 1993;16(1):14-17.

3. Tang DH, Colayco D, Piercy J, Patel V, Globe D, Chancellor MB Impact of urinary incontinence on health-related quality of life, daily activities, and healthcare resource utilization in patients with neurogenic detrusor overactivity. BMC Neurol. 2014;14:74.

4. Manack A, Motsko SP, Haag-Molkenteller C, et al. Epidemiology and healthcare utilization of neurogenic bladder patients in a US claims database. Neurourol Urodyn. 2011;30(3):395-401.

5. Fowler CJ, Griffiths D, de Groat WC. The neural control of micturition. Nat Rev Neurosci. 2008;9(6):453-466.

6. Rossier AB, Fam BA, Dibenedetto M, Sarkarati M. Urodynamics in spinal shock patients. J Urol. 1979;122(6):783-787.

7. Hiersemenzel LP, Curt A, Dietz V. From spinal shock to spasticity: neuronal adaptations to a spinal cord injury. Neurology. 2000;54(8): $1574-1582$.

8. McGuire EJ, Savastano JA. Long-term follow-up of spinal cord injury patients managed by intermittent catheterization. J Urol. 1983;129(4): 775-776.

9. Rudy DC, Awad SA, Downie JW. External sphincter dyssynergia: an abnormal continence reflex. J Urol. 1988;140(1):105-110.

10. Abdel-Azim M, Sullivan M, Yalla SV. Disorders of bladder function in spinal cord disease. Neurol Clin. 1991;9(3):727-740.

11. Clarke SJ, Thomas DG. Characteristics of the urethral pressure profile in flaccid male paraplegics. Br J Urol. 1981;53(2):157-161.

12. McGuire EJ, Morrissey SG. The development of neurogenic vesical dysfunction after experimental spinal cord injury or sacral rhizotomy in non-human primates. J Urol. 1982;128(6):1390-1393.

13. Cardenas DD, Mayo ME. Bacteriuria with fever after spinal cord injury. Arch Phys Med Rehabil. 1987;68(5 Pt 1):291-293. 
14. De Ridder DJ, Everaert K, Fernández LG, et al. Intermittent catheterisation with hydrophilic-coated catheters (SpeediCath) reduces the risk of clinical urinary tract infection in spinal cord injured patients: a prospective randomised parallel comparative trial. Eur Urol. 2005;48(6): 991-995.

15. Gribble MJ, Puterman ML. Prophylaxis of urinary tract infection in persons with recent spinal cord injury: a prospective, randomized, doubleblind, placebo-controlled study of trimethoprim-sulfamethoxazole. Am J Med. 1993;95(2):141-152.

16. Maynard FM, Diokno AC. Urinary infection and complications during clean intermittent catheterization following spinal cord injury. J Urol. 1984;132(5):943-946

17. Morton SC, Shekelle PG, Adams JL, et al. Antimicrobial prophylaxis for urinary tract infection in persons with spinal cord dysfunction. Arch Phys Med Rehabil. 2002;83(1):129-138.

18. Salomon J, Denys P, Merle C, et al. Prevention of urinary tract infection in spinal cord-injured patients: safety and efficacy of a weekly oral cyclic antibiotic (WOCA) programme with a 2 year follow-up - an observational prospective study. J Antimicrob Chemother. 2006;57(4): 784-788.

19. Lee BB, Haran MJ, Hunt LM, et al. Spinal-injured neuropathic bladder antisepsis (SINBA) trial. Spinal Cord. 2007;45(8):542-550.

20. Hull R, Rudy D, Donovan W, et al. Urinary tract infection prophylaxis using Escherichia coli 83972 in spinal cord injured patients. J Urol. 2000;163(3):872-877.

21. Buczyński AZ. Principles for urological management of SCI patients. Ortop Traumatol Rehabil. 2000;2(1):57-60.

22. Park YI, Linsenmeyer TA. A method to minimize indwelling catheter calcification and bladder stones in individuals with spinal cord injury. J Spinal Cord Med. 2001;24(2):105-108.

23. Chen Y, DeVivo MJ, Stover SL, Lloyd LK. Recurrent kidney stone: a 25-year follow-up study in persons with spinal cord injury. Urology. 2002;60(2):228-232.

24. Hackler RH, Dalton JJ Jr, Bunts RC. Changing concepts in the preservation of renal function in the paraplegic. J Urol. 1965;94: $107-111$.

25. Hess MJ, Zhan EH, Foo DK, Yalla SV. Bladder cancer in patients with spinal cord injury. J Spinal Cord Med. 2003;26(4):335-338.

26. Elliott S, Krassioukov A. Malignant autonomic dysreflexia in spinal cord injured men. Spinal Cord. 2006;44(6):386-392.

27. Altaweel W, Corcos J. Pathophysiology of autonomic dysreflexia. In: Corcos J, Schick E, editors. Textbook of the Neurogenic Bladder. London, UK: Martin Dunitz, Taylor and Francis Group; 2004.

28. Hou S, Rabchevsky AG. Autonomic consequences of spinal cord injury. Compr Physiol. 2014;4(4):1419-1453.

29. Panicker JN, de Sèze M, Fowler CJ. Rehabilitation in practice: neurogenic lower urinary tract dysfunction and its management. Clin Rehabil. 2010;24(7):579-589.

30. Welk B, Morrow S, Madarasz W, Baverstock R, Macnab J, Sequeira K. The validity and reliability of the neurogenic bladder symptom score. J Urol. 2014;192(2):452-457.

31. Klausner AP, Steers WD. The neurogenic bladder: an update with management strategies for primary care physicians. Med Clin North Am. 2011;95(1):111-120.

32. Mahfouz W, Corcos J. Management of detrusor external sphincter dyssynergia in neurogenic bladder. Eur J Phys Rehabil Med. 2011;47(4): 639-650.

33. Stöhrer M, Blok B, Castro-Diaz D, et al. EAU guidelines on neurogenic lower urinary tract dysfunction. Eur Urol. 2009;56(1):81-88.

34. Watanabe T, Rivas DA, Chancellor MB. Urodynamics of spinal cord injury. Urol Clin North Am. 1996;23(3):459-473.

35. McGuire EJ, Woodside JR, Borden TA, Weiss RM. Prognostic value of urodynamic testing in myelodysplastic patients. J Urol. 1981;126(2): 205-209.

36. Danforth TL, Ginsberg DA. Neurogenic lower urinary tract dysfunction: how, when, and with which patients do we use urodynamics? Urol Clin North Am. 2014;41(3):445-452.
37. Nosseir M, Hinkel A, Pannek J. Clinical usefulness of urodynamic assessment for maintenance of bladder function in patients with spinal cord injury. Neurourol Urodyn. 2007;26(2):228-233.

38. Marks BK, Goldman HB. Videourodynamics: indications and technique. Urol Clin North Am. 2014;41(3):383-391.

39. Liu CW, Attar KH, Gall A, Shah J, Craggs M. The relationship between bladder management and health-related quality of life in patients with spinal cord injury in the UK. Spinal Cord. 2010;48(4):319-324.

40. Engkasan JP, Ng CJ, Low WY. Factors influencing bladder management in male patients with spinal cord injury: a qualitative study. Spinal Cord. 2014;52(2):157-162.

41. Oh SJ, Ku JH, Jeon HG, Shin HI, Paik NJ, Yoo T. Health-related quality of life of patients using clean intermittent catheterization for neurogenic bladder secondary to spinal cord injury. Urology. 2005;65(2):306-310.

42. Thietje R, Giese R, Pouw M, et al. How does knowledge about spinal cord injury-related complications develop in subjects with spinal cord injury? A descriptive analysis in 214 patients. Spinal Cord. 2011;49(1): 43-48.

43. Vaidyanathan S, Singh G, Soni BM, et al. Do spinal cord injury patients always get the best treatment for neuropathic bladder after discharge from regional spinal injuries centres? Spinal Cord. 2004;42(8): $438-442$.

44. Chang SM, Hou CL, Dong DQ, Zhang H. Urologic status of 74 spinal cord injury patients from the 1976 Tangshan earthquake, and managed for over 20 years using the Credé maneuver. Spinal Cord. 2000;38(9): $552-554$.

45. Jackson AB, DeVivo M. Urological long-term follow-up in women with spinal cord injuries. Arch Phys Med Rehabil. 1992;73(11):1029-1035.

46. Hansen RB, Biering-Sørensen F, Kristensen JK. Bladder emptying over a period of 10-45 years after a traumatic spinal cord injury. Spinal Cord. 2004;42(11):631-637.

47. Rabadi MH, Aston C. Complications and urologic risks of neurogenic bladder in veterans with traumatic spinal cord injury. Spinal Cord. November 18, 2014. [Epub ahead of print.]

48. Wyndaele JJ. Complications of intermittent catheterization: their prevention and treatment. Spinal Cord. 2002;40(10):536-541.

49. Prieto-Fingerhut T, Banovac K, Lynne CM. A study comparing sterile and nonsterile urethral catheterization in patients with spinal cord injury. Rehabil Nurs. 1997;22(6):299-302.

50. Spinu A, Onose G, Daia C, et al. Intermittent catheterization in the management of post spinal cord injury (SCI) neurogenic bladder using new hydrophilic, with lubrication in close circuit devices - our own preliminary results. J Med Life. 2012;5(1):21-28.

51. Giannantoni A, Di Stasi SM, Scivoletto G, Virgili G, Dolci S, Porena M. Intermittent catheterization with a prelubricated catheter in spinal cord injured patients: a prospective randomized crossover study. J Urol. 2001;166(1):130-133.

52. $\mathrm{Ku} \mathrm{JH}, \mathrm{Oh} \mathrm{SJ}$, Jeon HG, et al. Sexual activity in Korean male patients on clean intermittent catheterization with neurogenic bladder due to spinal cord injury. Int J Urol. 2006;13(1):42-46.

53. Oh SJ, Shin HI, Paik NJ, Yoo T, Ku JH. Depressive symptoms of patients using clean intermittent catheterization for neurogenic bladder secondary to spinal cord injury. Spinal Cord. 2006;44(12):757-762.

54. Esclarín De Ruz A, García Leoni E, Herruzo Cabrera R. Epidemiology and risk factors for urinary tract infection in patients with spinal cord injury. J Urol. 2000;164(4):1285-1289.

55. West DA, Cummings JM, Longo WE, Virgo KS, Johnson FE, Parra RO. Role of chronic catheterization in the development of bladder cancer in patients with spinal cord injury. Urology. 1999;53(2):292-297.

56. Chao R, Clowers D, Mayo ME. Fate of upper urinary tracts in patients with indwelling catheters after spinal cord injury. Urology. 1993;42(3): 259-262.

57. Yang CC, Clowers DE. Screening cystoscopy in chronically catheterized spinal cord injury patients. Spinal Cord. 1999;37(3):204-207.

58. Ahluwalia RS, Johal N, Kouriefs C, Kooiman G, Montgomery BS, Plail RO. The surgical risk of suprapubic catheter insertion and longterm sequelae. Ann R Coll Surg Engl. 2006;88(2):210-213. 
59. Weld KJ, Dmochowski RR. Effect of bladder management on urological complications in spinal cord injured patients. J Urol. 2000;163(3): 768-772.

60. Mitsui T, Minami K, Furuno T, Morita H, Koyanagi T. Is suprapubic cystostomy an optimal urinary management in high quadriplegics? A comparative study of suprapubic cystostomy and clean intermittent catheterization. Eur Urol. 2000;38(4):434-438.

61. MacDiarmid SA, Arnold EP, Palmer NB, Anthony A. Management of spinal cord injured patients by indwelling suprapubic catheterization J Urol. 1995;154(2 Pt 1):492-494.

62. Weld KJ, Graney MJ, Dmochowski RR. Differences in bladder compliance with time and associations of bladder management with compliance in spinal cord injured patients. J Urol. 2000;163(4): $1228-1233$.

63. Bennett CJ, Young MN, Adkins RH, Diaz F. Comparison of bladder management complication outcomes in female spinal cord injury patients. J Urol. 1995;153(5):1458-1460.

64. del Popolo G, Mencarini M, Nelli F, Lazzeri M. Controversy over the pharmacological treatments of storage symptoms in spinal cord injury patients: a literature overview. Spinal Cord. 2012;50(1):8-13.

65. Madersbacher H, Mürtz G, Stöhrer M. Neurogenic detrusor overactivity in adults: a review on efficacy, tolerability and safety of oral antimuscarinics. Spinal Cord. 2013;51(6):432-441.

66. Kennelly MJ, Lemack GE, Foote JE, Trop CS. Efficacy and safety of oxybutynin transdermal system in spinal cord injury patients with neurogenic detrusor overactivity and incontinence: an open-label, dosetitration study. Urology. 2009;74(4):741-745.

67. George J, Tharion G, Richar J, Macaden AS, Thomas R, Bhattacharji S The effectiveness of intravesical oxybutynin, propantheline, and capsaicin in the management of neuropathic bladder following spinal cord injury. Scientific World Journal. 2007;7:1683-1690.

68. Nardulli R, Losavio E, Ranieri M, et al. Combined antimuscarinics for treatment of neurogenic overactive bladder. Int $J$ Immunopathol Pharmacol. 2012;25(1 Suppl):35S-41S

69. Bennett N, O'Leary M, Patel AS, Xavier M, Erickson JR, Chancellor MB. Can higher doses of oxybutynin improve efficacy in neurogenic bladder? J Urol. 2004;171(2 Pt 1):749-751.

70. Schurch B, Stöhrer M, Kramer G, Schmid DM, Gaul G, Hauri D. Botulinum-A toxin for treating detrusor hyperreflexia in spinal cord injured patients: a new alternative to anticholinergic drugs? Preliminary results. J Urol. 2000;164(3 Pt 1):692-697.

71. Cruz F, Herschorn S, Aliotta P, et al. Efficacy and safety of onabotulinumtoxinA in patients with urinary incontinence due to neurogenic detrusor overactivity: a randomised, double-blind, placebo-controlled trial. Eur Urol. 2011;60(4):742-750.

72. Reitz A, Stöhrer M, Kramer G, et al. European experience of 200 cases treated with botulinum-A toxin injections into the detrusor muscle for urinary incontinence due to neurogenic detrusor overactivity. Eur Urol. 2004;45(4):510-515.

73. Schurch B, de Sèze M, Denys $P$, et al. Botulinum toxin type A is a safe and effective treatment for neurogenic urinary incontinence: results of a single treatment, randomized, placebo controlled 6-month study. J Urol. 2005;174(1):196-200.

74. Grosse J, Kramer G, Stöhrer M. Success of repeat detrusor injections of botulinum a toxin in patients with severe neurogenic detrusor overactivity and incontinence. Eur Urol. 2005;47(5): 653-659.

75. Kuo HC, Liu SH. Effect of repeated detrusor onabotulinumtoxinA injections on bladder and renal function in patients with chronic spinal cord injuries. Neurourol Urodyn. 2011;30(8):1541-1545.

76. Del Popolo G, Filocamo MT, Li Marzi V, et al. Neurogenic detrusor overactivity treated with english botulinum toxin a: 8-year experience of one single centre. Eur Urol. 2008;53(5):1013-1019.

77. Giannantoni A, Mearini E, Del Zingaro M, Porena M. Six-year follow-up of botulinum toxin A intradetrusorial injections in patients with refractory neurogenic detrusor overactivity: clinical and urodynamic results. Eur Urol. 2009;55(3):705-711.
78. US Food and Drug Administration. FDA approves Botox to treat specific form of urinary incontinence. Available from: http://www. fda.gov/NewsEvents/Newsroom/PressAnnouncements/ucm269509. htm. Accessed March 8, 2015.

79. Madersbacher S, Schmidt J, Eberle JM, et al. Long-term outcome of ileal conduit diversion. J Urol. 2003;169(3):985-990.

80. Biers SM, Venn SN, Greenwell TJ. The past, present and future of augmentation cystoplasty. BJU Int. 2012;109(9):1280-1293.

81. Linder A, Leach GE, Raz S. Augmentation cystoplasty in the treatment of neurogenic bladder dysfunction. J Urol. 1983;129(3):491-493.

82. Gurung PM, Attar KH, Abdul-Rahman A, Morris T, Hamid R, Shah PJ. Long-term outcomes of augmentation ileocystoplasty in patients with spinal cord injury: a minimum of 10 years of follow-up. BJU Int. 2012;109(8):1236-1242.

83. Chen JL, Kuo HC. Long-term outcomes of augmentation enterocystoplasty with an ileal segment in patients with spinal cord injury. J Formos Med Assoc. 2009;108(6):475-480.

84. Sidi AA, Becher EF, Reddy PK, Dykstra DD. Augmentation enterocystoplasty for the management of voiding dysfunction in spinal cord injury patients. J Urol. 1990;143(1):83-85.

85. Chartier-Kastler EJ, Mongiat-Artus P, Bitker MO, Chancellor MB, Richard F, Denys P. Long-term results of augmentation cystoplasty in spinal cord injury patients. Spinal Cord. 2000;38(8):490-494.

86. Gobeaux N, Yates DR, Denys P, Even-Schneider A, Richard F, Chartier-Kastler E. Supratrigonal cystectomy with Hautmann pouch as treatment for neurogenic bladder in spinal cord injury patients: longterm functional results. Neurourol Urodyn. 2012;31(5):672-676.

87. Gill IS, Rackley RR, Meraney AM, Marcello PW, Sung GT. Laparoscopic enterocystoplasty. Urology. 2000;55(2):178-181.

88. Rackley RR, Abdelmalak JB. Laparoscopic augmentation cystoplasty. Surgical technique. Urol Clin North Am. 2001;28(3):663-670.

89. Kang IS, Lee JW, Seo IY. Robot-assisted laparoscopic augmentation ileocystoplasty: a case report. Int Neurourol J. 2010;14(1):61-64.

90. McDougal WS. Metabolic complications of urinary intestinal diversion. J Urol. 1992;147(5):1199-1208.

91. Wagstaff KE, Woodhouse CR, Duffy PG, Ransley PG. Delayed linear growth in children with enterocystoplasties. Br J Urol. 1992;69(3): 314-317.

92. Mundy AR, Nurse DE. Calcium balance, growth and skeletal mineralisation in patients with cystoplasties. Br J Urol. 1992;69(3):257-259.

93. Blyth B, Ewalt DH, Duckett JW, Snyder HM 3rd. Lithogenic properties of enterocystoplasty. J Urol. 1992;148(2 Pt 2):575-577.

94. Mathoera RB, Kok DJ, Nijman RJ. Bladder calculi in augmentation cystoplasty in children. Urology. 2000;56(3):482-487.

95. Herschorn S, Hewitt RJ. Patient perspective of long-term outcome of augmentation cystoplasty for neurogenic bladder. Urology. 1998;52(4):672-678.

96. Rosenbaum DH, Cain MP, Kaefer M, et al. Ileal enterocystoplasty and B12 deficiency in pediatric patients. J Urol. 2008;179(4):1544-1547.

97. Hamid R, Greenwell TJ, Nethercliffe JM, Freeman A, Venn SN, Woodhouse CR. Routine surveillance cystoscopy for patients with augmentation and substitution cystoplasty for benign urological conditions: is it necessary? BJU Int. 2009;104(3):392-395.

98. Sung MT, Zhang S, Lopez-Beltran A, et al. Urothelial carcinoma following augmentation cystoplasty: an aggressive variant with distinct clinicopathological characteristics and molecular genetic alterations. Histopathology. 2009;55(2):161-173.

99. Higuchi TT, Granberg CF, Fox JA, Husmann DA. Augmentation cystoplasty and risk of neoplasia: fact, fiction and controversy. J Urol. 2010;184(6):2492-2496.

100. Adams MC, Mitchell ME, Rink RC. Gastrocystoplasty: an alternative solution to the problem of urological reconstruction in the severely compromised patient. J Urol. 1988;140(5 Pt 2):1152-1156.

101. Nguyen DH, Bain MA, Salmonson KL, Ganesan GS, Burns MW, Mitchell ME. The syndrome of dysuria and hematuria in pediatric urinary reconstruction with stomach. $J$ Urol. 1993;150(2 Pt 2): 707-709. 
102. Kinahan TJ, Khoury AE, McLorie GA, Churchill BM. Omeprazole in post-gastrocystoplasty metabolic alkalosis and aciduria. $J$ Urol. 1992;147(2):435-437.

103. Al-Azzawi Y, Galloway N, Keilin S. Management of bleedingassociated severe gastritis of the gastric mucosa in a patient with a gastrocystoplasty. J Clin Gastroenterol. 2014;48(4):360-361.

104. Husmann DA. Malignancy after gastrointestinal augmentation in childhood. Ther Adv Urol. 2009;1(1):5-11.

105. Castellan M, Gosalbez R, Bar-YosefY, Labbie A. Complications after use of gastric segments for lower urinary tract reconstruction. J Urol. 2012;187(5):1823-1827.

106. Cartwright PC, Snow BW. Bladder autoaugmentation: early clinical experience. J Urol. 1989;142(2 Pt 2):505-508.

107. Garibay JT, Manivel JC, González R. Effect of seromuscular colocystoplasty lined with urothelium and partial detrusorectomy on a new canine model of reduced bladder capacity. J Urol. 1995; 154(2 Pt 2):903-906.

108. Swami KS, Feneley RC, Hammonds JC, Abrams P. Detrusor myectomy for detrusor overactivity: a minimum 1-year follow-up. $\mathrm{Br} J$ Urol. 1998;81(1):68-72.

109. Potter JM, Duffy PG, Gordon EM, Malone PR. Detrusor myotomy: a 5-year review in unstable and non-compliant bladders. BJU Int. 2002;89(9):932-935.

110. MacNeily AE, Afshar K, Coleman GU, Johnson HW. Autoaugmentation by detrusor myotomy: its lack of effectiveness in the management of congenital neuropathic bladder. J Urol. 2003;170(4 Pt 2): 1643-1646.

111. Gurocak S, De Gier RP, Feitz W. Bladder augmentation without integration of intact bowel segments: critical review and future perspectives. J Urol. 2007;177(3):839-844.

112. Buson H, Manivel JC, Dayanç M, Long R, Gonzalez R. Seromuscular colocystoplasty lined with urothelium: experimental study. Urology. 1994;44(5):743-748

113. Dewan PA, Stefanek W. Autoaugmentation gastrocystoplasty: early clinical results. Br J Urol. 1994;74(4):460-464.

114. Jednak R, Schimke CM, Barroso U Jr, Barthold JS, González R. Further experience with seromuscular colocystoplasty lined with urothelium. J Urol. 2000;164(6):2045-2049.

115. González R, Ludwikowski B, Horst M. Determinants of success and failure of seromuscular colocystoplasty lined with urothelium. J Urol. 2009;182(4 Suppl):1781-1784.

116. Lima SV, Araujo LA, Montoro M, Maciel A, Vilar FO. The use of demucosalized bowel to augment small contracted bladders. Br J Urol. 1998;82(3):436-439

117. Lima SV, Araújo LA, Vilar FO. Nonsecretory intestinocystoplasty: a 10-year experience. J Urol. 2004;171(6 Pt 2):2636-2639.

118. Chartier Kastler E, Genevois S, Gamé X, et al. Treatment of neurogenic male urinary incontinence related to intrinsic sphincter insufficiency with an artificial urinary sphincter: a French retrospective multicentre study. BJU Int. 2011;107(3):426-432.

119. Bersch U, Göcking K, Pannek J. The artificial urinary sphincter in patients with spinal cord lesion: description of a modified technique and clinical results. Eur Urol. 2009;55(3):687-693.

120. Murphy S, Rea D, O'Mahony J, et al. A comparison of the functional durability of the AMS 800 artificial urinary sphincter between cases with and without an underlying neurogenic aetiology. Ir J Med Sci. 2003;172(3):136-138.

121. Gonzalez R, Nguyen DH, Koleilat N, Sidi AA. Compatibility of enterocystoplasty and the artificial urinary sphincter. J Urol. 1989; 142(2 Pt 2):502-504.

122. Yates DR, Phé V, Rouprêt M, et al. Robot-assisted laparoscopic artificial urinary sphincter insertion in men with neurogenic stress urinary incontinence. BJU Int. 2013;111(7):1175-1179.

123. Pannek J, Bartel P, Gocking K. Clinical usefulness of the transobturator sub-urethral tape in the treatment of stress urinary incontinence in female patients with spinal cord lesion. J Spinal Cord Med. 2012;35(2): $102-106$.
124. Daneshmand S, Ginsberg DA, Bennet JK, et al. Puboprostatic sling repair for treatment of urethral incompetence in adult neurogenic incontinence. J Urol. 2003;169(1):199-202.

125. Perkash I. Transurethral sphincterotomy provides significant relief in autonomic dysreflexia in spinal cord injured male patients: long-term follow-up results. J Urol. 2007;177(3):1026-1029.

126. Moeller BA. Some observations of 31 spinal cord injury patients on whom the Bricker procedure was performed. Paraplegia. 1977;15(3): 230-237.

127. Comarr AE. Renal complications of the ileal conduit and cutaneous vesicostomy among patients with traumatic cord bladders. J Urol. 1972;107(5):762-765.

128. Koziol I, Hackler RH. Cutaneous ureteroileostomy in the spinal cord injured patient: a 15-year experience. J Urol. 1975;114(5): 709-711.

129. Kambouris AA, Allaben RD, Carpenter WS, Shumaker EJ. Ileal loop ureteroileostomy in patients with neurogenic bladder. Personal experience with 54 patients. Am J Surg. 1976;131(2):224-227.

130. Chartier-Kastler EJ, Mozer P, Denys P, Bitker MO, Haertig A, Richard F. Neurogenic bladder management and cutaneous noncontinent ileal conduit. Spinal Cord. 2002;40(9):443-448.

131. Guillotreau J, Castel-Lacanal E, Roumiguié M, et al. Prospective study of the impact on quality of life of cystectomy with ileal conduit urinary diversion for neurogenic bladder dysfunction. Neurourol Urodyn. 2011;30(8):1503-1506.

132. Radziszewski K. Outcomes of electrical stimulation of the neurogenic bladder: results of a two-year follow-up study. NeuroRehabilitation. 2013;32(4):867-873.

133. Lin H, Hou C, Zhen X, Xu Z. Clinical study of reconstructed bladder innervation below the level of spinal cord injury to produce urination by Achilles tendon-to-bladder reflex contractions. J Neurosurg Spine. 2009; 10(5):452-457.

134. Lin $\mathrm{H}, \mathrm{Hou} \mathrm{C}$. Transfer of normal $\mathrm{S} 1$ nerve root to reinnervate atonic bladder due to conus medullaris injury. Muscle Nerve. 2013;47(2): 241-245.

135. Stenzl A, Strasser H, Klima G, et al. Reconstruction of the lower urinary tract using autologous muscle transfer and cell seeding: current status and future perspectives. World J Urol. 2000;18(1):44-50.

136. Chancellor MB, Rivas DA, Linsenmeyer T, et al. Multicenter trial in North America of UroLume urinary sphincter prosthesis. J Urol. 1994;152(3):924-930.

137. Rivas DA, Chancellor MB, Bagley D. Prospective comparison of external sphincter prosthesis placement and external sphincterotomy in men with spinal cord injury. J Endourol. 1994;8(2):89-93.

138. Mehta SS, Tophill PR. Memokath stents for the treatment of detrusor sphincter dyssynergia (DSD) in men with spinal cord injury: the Princess Royal Spinal Injuries Unit 10-year experience. Spinal Cord. 2006;44(1):1-6.

139. Pokrywczynska M, Adamowicz J, Sharma AK, Drewa T. Human urinary bladder regeneration through tissue engineering - an analysis of 131 clinical cases. Exp Biol Med (Maywood). 2014;239(3): 264-271.

140. Sloff M, Simaioforidis V, de Vries R, Oosterwijk E, Feitz W. Tissue engineering of the bladder - reality or myth? A systematic review. J Urol. 2014;192(4):1035-1042.

141. Atala A, Bauer SB, Soker S, Yoo JJ, Retik AB. Tissue-engineered autologous bladders for patients needing cystoplasty. Lancet. 2006;367(9518):1241-1246.

142. Joseph DB, Borer JG, De Filippo RE, Hodges SJ, McLorie GA. Autologous cell seeded biodegradable scaffold for augmentation cystoplasty: phase II study in children and adolescents with spina bifida. J Urol. 2014;191(5):1389-1395.

143. Zhang F, Liao L. Tissue engineered cystoplasty augmentation for treatment of neurogenic bladder using small intestinal submucosa: an exploratory study. $J$ Urol. 2014;192(2):544-550. 
Research and Reports in Urology

\section{Publish your work in this journal}

Research and Reports in Urology is an international, peer-reviewed, open access journal publishing original research, reports, editorials, reviews and commentaries on all aspects of adult and pediatric urology in the clinic and laboratory including the following topics: Pathology, pathophysiology of urological disease; Investigation and treatment of

urological disease; Pharmacology of drugs used for the treatment of urological disease. The manuscript management system is completely online and includes a very quick and fair peer-review system, which is all easy to use. Visit http://www.dovepress.com/testimonials.php to read real quotes from published authors.

Submit your manuscript here: http://www.dovepress.com/research-and-reports-in-urology-journal 